OPEN ACCESS

Edited by:

Yun-Cai Liu,

Tsinghua University, China

Reviewed by:

Xindong Liu,

Army Medical University, China

Youn Soo Choi,

Seoul National University College of

Medicine, South Korea

*Correspondence:

Chuanxin Huang

huangcx@shsmu.edu.cn

†These authors have contributed equally to this work

Specialty section:

This article was submitted to T Cell Biology,

a section of the journal

Frontiers in Immunology

Received: 20 May 2019

Accepted: 14 August 2019 Published: 04 September 2019

Citation:

Zhang $H$, Hu Q, Zhang M, Yang F, Peng C, Zhang $Z$ and Huang C (2019) Bach2 Deficiency Leads to

Spontaneous Expansion of IL-4-Producing T Follicular Helper Cells and Autoimmunity.

Front. Immunol. 10:2050.

doi: 10.3389/fimmu.2019.02050

\title{
Bach2 Deficiency Leads to Spontaneous Expansion of IL-4-Producing T Follicular Helper Cells and Autoimmunity
}

\begin{abstract}
Heng Zhang ${ }^{1+}$, Qianwen $\mathrm{Hu}^{1+}$, Min Zhang ${ }^{2 \dagger}$, Fang Yang ${ }^{1}$, Cheng Peng ${ }^{1}$, Zhen Zhang ${ }^{2}$ and Chuanxin Huang ${ }^{\text {1* }}$

${ }^{1}$ Key Laboratory of Cell Differentiation and Apoptosis of Chinese Ministry of Education, Department of Immunology and Microbiology, Faculty of Basic Medicine, Shanghai Institute of Immunology, Shanghai Jiao Tong University School of Medicine, Shanghai, China, ${ }^{2}$ Shanghai Children's Medical Center, Pediatric Translational Medicine Institute, Shanghai Pediatric Congenital Heart Disease Institute, Shanghai Jiao Tong University, School of Medicine, Shanghai, China
\end{abstract}

The transcription factor Bach2 is a susceptible gene for numerous autoimmune diseases including systemic lupus erythematosus (SLE). Bach2-/- mice can develop a lupus-like autoimmune disease. However, the exact cellular and molecular mechanisms via which Bach2 protects the hosts from developing autoimmunity remains incompletely understood. Here, we report that Bach2 ablation on T cells, but not B cells, resulted in humoral autoimmunity, and this was associated with expansion of $T$ follicular helper (Tfh) cells and abnormal germinal centers. Bach2 was down-regulated in Tfh cells and directly suppressed by the Tfh-defining transcription factor BCL6. Mechanistically, Bach2 directly suppresses the transcription of $\mathrm{Cxcr} 5$ and $\mathrm{C}-\mathrm{Maf}$, two key regulators of Tfh cell differentiation. Bach2-deficient Tfh cells were skewed toward the IL-4-producing subset, which induced IgG1 and IgE isotype switching of B cells. Heterozygous Bcl6 deficiency reduced the formation of germinal center and autoantibodies, and ameliorated the pathology in Bach2-deficient mice. Our findings identify Bach2 as a crucial negative regulator of Tfh cells at steady state and prove that Bach2 controls autoimmunity in part by restraining accumulation of pathogenic Tfh cells.

Keywords: Bach2, T follicular helper cells, IL-4, autoimmunity, BCL6

\section{INTRODUCTION}

The transcription factor Bach2 belongs to the BTB and Cap'n'collar (CNC) gene family and functions within multiple innate and adaptive lineages to control immune responses (1). Genetic polymorphisms within the $\mathrm{BACH} 2$ gene locus in human are associated with numerous autoimmune and allergic diseases including asthma (2), vitiligo (3), multiple sclerosis (4), type I diabetes (5), and systemic lupus erythematosus (SLE) (6). Bach $2^{-1-}$ mice developed autoantibodies and spontaneous lethal inflammatory diseases (7), suggesting an essential role of Bach2 in controlling autoimmunity. Bach2 is highly expressed in GC B cells and promotes antibody class switching and suppresses plasma cell differentiation $(8,9)$. Bach2 is also expressed by $\mathrm{T}$ cells, and directs $\mathrm{T}$ helper (Th) cell differentiation, homeostasis, and effector functions (1). Bach2 constrains full effector differentiation within Th1, Th2, and Th17 cells in vitro (7). Bach2 maintains Th cells 
in a naïve state by suppressing effector memory-related genes (10). Bach2 promotes Foxp $3^{+}$regulatory $\mathrm{T}$ (Treg) cell differentiation and enhances Treg-mediated immunity $(7,11)$. More recently, we reported that SUMO-specific protease 3 (SENP3) act as a pivotal regulator of Treg cells by controlling the SUMOylation and nuclear localization of Bach2 (12). In addition, Bach2 suppresses the differentiation of Th2 cells, and Bach2deficient mice develop lethal lung-specific Th2-type allergic inflammation $(13,14)$. These findings help explain the emergence of Bach2 as a key suppressor of autoimmunity.

$\mathrm{T}$ follicular helper (Tfh) cells, a unique subset of CD4 helper $\mathrm{T}$ cells, are specialized in providing cognate help to $\mathrm{B}$ cells to form GCs. Within GCs, Tfh cells interact with B cells through the co-stimulatory and co-inhibitory molecules, including CD40L, ICOS, and programmed cell death protein 1 (PD-1), to facilitate the selection and maturation of high-affinity $\mathrm{B}$ cells $(15,16)$. However, excessive Tfh cells impair positive selection by reducing competition among B cells for T cell help, thus yielding a lower threshold for selection that allows for emergence of self-reactive clones. Aberrant expansion of Tfh cells results in pathogenic autoantibodies and is frequently associated with autoimmune diseases, including SLE (17-19). Numerous mouse studies have supported a causal role of Th cells in autoimmune diseases (20-22). In addition, increased blood memory Tfh cells were frequently observed in human autoimmune diseases such as SLE, and positively correlated with serum autoantibody titers and disease severity $(23,24)$, suggesting an important role of Tfh cells in the pathogenesis of these diseases. Tfh cells are proposed to be potential therapeutic targets in human autoimmune diseases.

Tfh cells are generally considered to be of a separate Th cell lineage and arise from naive $\mathrm{CD} 4^{+} \mathrm{T}$ cells with sequential steps in response to T-cell-dependent antigen $(15,16)$. Naive $\mathrm{CD}^{+}{ }^{+} \mathrm{T}$ cells are primed by dendritic cells and up-regulates the chemokine (C-X-C motif) receptor CXCR5, which enables them to migrate into $\mathrm{B}$ cell follicles to further differentiate into Tfh cells. However, Tfh cells can also be generated from the conversion of other effector $\mathrm{T}$ cells under the conditions of chronic and sustained antigenic stimulation $(25,26)$. Tfh cell differentiation is tightly controlled by numerous lineage-specific transcription factors including B cell lymphoma 6 (BCL6), cMaf, and Blimp1 $(27,28)$. BCL6 is a master transcription factor of Tfh cells, and Tfh cell differentiation is completely abrogated in Bcl6-deficient CD4 ${ }^{+} \mathrm{T}$ cells (29-31). c-Maf acts as a positive regulator of Tfh cell differentiation in mice and humans, and induces the expression of many Tfh-related genes including Cxcr5 and $I L-21$ (32-34). Interestingly, some regulators of Tfh cell differentiation, such as transcription factor Ets1 (35), are encoded by human autoimmunity-prone genes, and their deficiency causes Tfh-driven humoral autoimmune diseases in mice.

In this study, we report that genetic deletion of Bach2 in $\mathrm{T}$ cells, but not in $\mathrm{B}$ cells, recapitulated the lupus-like autoimmunity in Bach2 $2^{-/-}$mice. Bach 2 deficiency in $\mathrm{T}$ cells results in spontaneous accumulation of IL-4-producing Tfh cells. We also provide the evidence that Bach 2 controls autoimmunity in part by restraining aberrant Tfh cell formation.

\section{MATERIALS AND METHODS}

\section{Mice}

Bach $2^{\mathrm{fl} / \mathrm{fl}}$ mice (ES Clone ID: EPD0689_1_H02) were generated at the Wellcome Trust Sanger Institute and the neo cassette was removed after crossing with FLPe transgenic mice (The Jackson Laboratory). Cd4-Cre, Cd19-Cre, and ERT2-Cre transgenic mice were from The Jackson Laboratory. $B c l 6^{\mathrm{fl} / \mathrm{fl}}$ mice are described previously (36). All mice were crossed on a C57BL/6J background. All mice were maintained in a specific pathogenfree (SPF) facility, and all animal experiments were in accordance with protocols approved by the Institutional Animal care and Use Committee (IACUC) of Shanghai Jiao Tong University, School of Medicine.

\section{Flow Cytometry and Antibodies}

Single-cell suspensions of spleens, MLNs, and PPs were prepared from fresh tissues by standard procedures and surface-stained in FACS buffer with monoclonal antibodies. The following antibodies were obtained from eBioscience, BD PharMingen, or BioLegend: anti-B220-PE, FITC, BV650 or APC (RA3-6B2), anti-Fas PE-Cy7 (Jo2), anti-CD38-PE or PerCP/Cy5.5, anti-GL7FITC (GL7), anti-IgM-APC (II/41), anti-IgG1-FITC (RMG11), anti-IgE-FITC (RME-1), anti-CD86-APC (GL1), anti-ICOSFITC (7E.17G9), anti-CD44-APC (1M7), anti-CD62L-FITC (MEL-14), anti-PD1-PE or FITC (J43), and anti-CD4-APC or APC-CY7 (GK1.5). CXCR5 was stained with biotinylated anti-CXCR5 (clone 2G8) and streptavidin-conjugated PE, $\mathrm{APC}$, or PE/CY7 (BD Biosciences). For intracellular staining, cells were fixed and permeabilized with "Foxp3 staining buffer set" (eBioscience) following the manufacturer's protocol and then stained with anti-Foxp3-PE (FJK-16s, ebiosciences) and anti-BCL6-PerCP/CY5.5. To identify cytokine secretion, lymphocytes were routinely prepared and stimulated with PMA (phorbol 12-myristate 13-acetate, $20 \mathrm{ng} / \mathrm{ml}$, Invitrogen) and inomycin $(1 \mu \mathrm{g} / \mathrm{ml}$, Invitrogen) in the presence of Golgi-Plug ( $1 \mu \mathrm{g} / \mathrm{ml}$, Invitrogen) for $5 \mathrm{~h}$. Cells were stained with anti-CD4 antibodies, followed by permeabilization in Fix/Perm buffer (BD, Pharmingen), and intracellular staining in Perm/Wash buffer (BD Pharmingen) with anti-IL-4-PE (11b11) and antiIFN-gamma-FITC (XMG1.2). NP-PE was from Biosearch Technologies. FACS analysis was performed on a Fortessa II (BD), and data were analyzed with FlowJo software (Tree Star).

\section{Histology}

Kidneys were fixed in $10 \%$ neutral buffered formalin, embedded in paraffin, sectioned at $7 \mu \mathrm{m}$, and stained with hematoxylin and eosin. Immunohistochemistry was performed as described previously (9). Briefly, after antigen retrieval and pretreatment with $3 \%$ hydrogen peroxide, tissue sections $(7 \mu \mathrm{m})$ were then incubated with biotin-conjugated PNA (Vector Laboratories) overnight at $4^{\circ} \mathrm{C}$, followed by streptavidin-alkaline phosphatase and detected by the Alkaline Phosphatase Substrate Kit III (Vector Laboratories). The sections were then boiled for $10 \mathrm{~min}$, incubated with biotin-conjugated anti-B220 (RA3-6B2, Caltag metsystems), followed by streptavidin-HRP and developed using DAB kit. To visualize IgG position in the glomeruli, kidney 
sections $(7 \mu \mathrm{m})$ were incubated with blocking buffer and stained with HRP-conjugated anti-mouse IgG antibody (Jackson ImmunoResearch), followed by streptavidin-HRP and developed using DAB kit. Images were taken using a color camera (AxioCam; Carl Zeiss Microimaging) and were analyzed using Axiovision software (Carl Zeiss Microimaging).

\section{Immunization and Tamoxifen Treatment}

Mice were immunized intraperitoneally (i.p.) with SRBCs $(1 \times$ $10^{8}$ cells per mouse). Tamoxifen $(80 \mathrm{mg} / \mathrm{kg}$, Sigma) in corn oil (Sigma) was given by oral gavage on day 8 post immunization to induce the activity of the Cre recombinase. Mice were analyzed on day 5 after tamoxifen treatment.

\section{Mixed Bone Marrow Chimera}

To determine the intrinsic role of Bach2, a mixture of congenic CD $45.1^{+}$wild-type bone marrow cells (80\%) together with CD $45.2^{+}$tested bone marrow cells $(20 \%)$ either from WT or Bach $2^{\triangle C D 4}$ mice were transferred intravenously into lethally irradiated (5.5 Gy, twice) CD45.1 ${ }^{+}$WT recipient mice. After at least 8 weeks of bone marrow reconstitution, the recipients were subjected for analysis.

\section{RNA Sequencing and Data Analysis}

A total of $1-3 \times 10^{4}$ Tfh cells $\left(\mathrm{CD} 4^{+} \mathrm{B} 220^{-} \mathrm{CD} 44^{+} \mathrm{PD}\right.$ $1^{+} \mathrm{CXCR}^{+}$) were sorted from the MLNs of WT and Bach $2^{\mathrm{fl} / \mathrm{fl}} \mathrm{Cd} 4$-cre mice using a FACSAria II cell sorter (BD Biosciences) at the core facility of Shanghai Institute of Immunology. cDNA was synthesized and amplified using the SMARTer Ultra Low RNA Kit for Illumina Sequencing (Clontech). The library for mRNA sequencing was generated using Illumnia TruSeq Preparation Kit (RS-122-2001) and sequenced using Illumnia Nextseq500 sequencer. The mapping rate was $96 \%$ overall across all the samples in the dataset. HTSeq was used to quantify the gene expression counts from Tophat 2 alignment files. Differential expression analysis was performed on the count data using $\mathrm{R}$ package DESeq2. $P$ values obtained from multiple tests were adjusted using Benjamini-Hochberg correction. Significantly differentially expressed genes are defined by a Benjamini-Hochberg corrected $P$ value $<0.01$ and fold change $>2$.

\section{Enzyme-Linked Immunosorbent Assay (ELISA) and Detection of Autoantibodies}

Serum titers of immunoglobulin subclasses were determined by specific ELISA kits (SouthernBiotech) according to the manufacturer's protocol. To detect anti-dsDNA autoantibodies in sera, high-binding ELISA plates were coated overnight with $2 \mu \mathrm{g} / \mathrm{ml}$ dsDNA from calf thymus (Sigma-Aldrich). Coated plates were blocked with $1 \%$ BSA and $0.5 \%$ gelatin in TBS for $2 \mathrm{~h}$ at room temperature, and diluted samples were incubated overnight at $4^{\circ} \mathrm{C}$ in TBS with $1 \%$ BSA. Bound anti-dsDNA antibodies were detected with AP-conjugated anti-mouse IgG (Jackson ImmunoResearch) and streptavidin-HRP (Bioresearch) followed by TMB substrate solution (eBioscience). Absorbance was measured at $450 \mathrm{~nm}$. Serum titers of anti-ANA antibodies were determined by ANA Hep Screen ELISA kit (Demeditec) according to the manufacturer's protocol.

\section{Naive CD4 ${ }^{+} \mathbf{T}$ Cell Isolation and Differentiation in vitro}

Naive CD4 ${ }^{+} \mathrm{T}\left(\mathrm{CD} 44^{\text {low }} \mathrm{CD} 62 \mathrm{~L}^{\text {high }} \mathrm{CD} 25^{-}\right)$cells were purified using a $\mathrm{CD}^{+}$naive $\mathrm{T}$ cell negative isolation kit according to the manufacturer's protocol (STEMCELL Technologies). The in vitro differentiation experiments were performed as previously described. Naive $\mathrm{CD} 4^{+}$T cells were stimulated with immobilized anti-CD3 $(5 \mu \mathrm{g} / \mathrm{ml} ; 145-2 \mathrm{C} 11$; eBioscience) and anti-CD28 ( $5 \mu \mathrm{g} / \mathrm{ml} ; 37.51$; eBioscience) for 2 days. Then, the cells were washed and transferred to a new plate and further expanded in medium with hIL-2 (50 U/ml, R\&D Systems) for 2 days. For Tfh-like cell differentiation, naive $\mathrm{CD} 4^{+} \mathrm{T}$ cells were activated with anti-CD3 and anti-CD28 as above and treated with $20 \mathrm{ng} / \mathrm{ml}$ IL-6 (R\&D Systems), $20 \mathrm{ng} / \mathrm{ml} \mathrm{IL-21} \mathrm{(R \& D} \mathrm{Systems),} 10 \mu \mathrm{g} / \mathrm{ml}$ anti-IL-4 (11B11, eBioscience), $10 \mu \mathrm{g} / \mathrm{ml}$ anti-IFN- $\gamma$ (XMG1.2, eBioscience), and $20 \mu \mathrm{g} / \mathrm{ml}$ anti-TGF- $\beta$ (1D11, R\&D Systems) for 4 days.

\section{RT-qPCR}

Total RNA was prepared with Trizol (invitrogen) and cDNA was synthesized using Superscript reverse transcriptase and random primers (Invitrogen). Quantitative PCR (qPCR) was performed using Power SYBR Green PCR master mix (Vazyme). The sequences of gene-specific primers are listed in the Supplementary Information. All reactions were performed in triplicate and results were calculated by the change-in-threshold $\left(2^{-\Delta \Delta \mathrm{CT}}\right)$ method with $A c t \beta$ as housekeeping reference gene.

\section{ChIP-qPCR}

Spleen naive $\mathrm{CD}^{+} \mathrm{T}$ cells were stimulated with immobilized anti-CD3 $(5 \mu \mathrm{g} / \mathrm{ml} ; 145-2 \mathrm{C} 11$; eBioscience $)$ and anti-CD28 ( $5 \mu \mathrm{g} / \mathrm{ml}$; 37.51; eBioscience) antibodies for 2 days before analysis. Human Tfh cells were isolated from tonsils as described previously (37). Cells were cross-linked with $1 \%$ formaldehyde and neutralized with $0.125 \mathrm{M}$ glycine. Cell lysates were sonicated to $300-500 \mathrm{bp}$ and immunoprecipitations were performed with anti-BCL6 (N-3; Santa Cruz Biotechnology Inc.), antiBACH2 (9), or IgG as a control. After complete washing, immunoprecipitated DNA was eluted in elution buffer and reversely cross-linked at $65^{\circ} \mathrm{C}$ overnight. DNA was purified and quantified by real-time PCR. Gene-specific primers are listed in Table S1.

\section{Statistical Analysis}

Student's $t$-test was performed for statistical analysis. The software GraphPad Prism 5 was used for this analysis. $P$ values higher than 0.05 are considered to be not significant.

\section{RESULTS}

\section{Bach2 Ablation in T Cells Is Sufficient to Recapitulate the Autoimmunity in Bach2-/- Mice $^{-1}$}

Bach $2^{-/-}$mice have been known to develop autoantibodies and age-related lethal autoimmunity (7). To determine which types of immune cells play key roles in disease development, we generated cell-type-specific Bach2-deficient mice where Bach2 was deleted in $\mathrm{CD} 4^{+} \mathrm{T}$ cells $\left(\right.$ Bach $\left.2^{\triangle C D 4}\right)$ or B cells $\left(\right.$ Bach $\left.2^{\triangle C D 19}\right)$. 
Bach $2^{\triangle C D 4}$ mice were undistinguishable from the $C d 4$-Cre mice (designated WT) littermates by 2 months of age. From 3 months of age, Bach $2^{\triangle C D 4}$ mice spontaneously developed a progressive wasting disease that resulted in diminished survival compared to WT mice (Figures 1A,B). Two- to 3-month-old Bach $2^{\triangle C D 4}$ mice generated higher concentrations of antibodies to doublestranded DNA (anti-dsDNA) and nuclear antigen (anti-ANA) in their serum (Figure 1C), which are the hallmarks of autoimmune diseases in humans. In contrast, these abnormalities were not detected in Bach2 $2^{\triangle C D 19}$ mice (Figures 1A-C). Two- to 3-month-old Bach $2^{\triangle C D 4}$ mice contained significantly higher amounts of serum IgM, IgG1, and IgA compared to agematched WT controls (Figure 1D). However, the titers of serum IgG2b, IgG2c, and IgG3 were comparable between the two groups (Figure 1D). We also detected higher titers of antidsDNA and anti-ANA IgG1, but not other IgG2 subclasses, in the serum of these Bach2 $2^{\triangle C D 4}$ mice (Figure $1 \mathbf{E}$ and data not shown). Aged Bach $2^{\triangle C D 4}$ mice displayed prominent IgG deposits in kidney glomeruli (Figure 1F), and spontaneously developed splenomegaly and lymphadenopathy (Figure 1G). These abnormalities became prominent when they reached 5-6 months of age and showed signs of illness. In summary, these results demonstrate that $\mathrm{Bach} 2$ in $\mathrm{T}$ cells is essential to prevent humoral autoimmunity in mice.

\section{Bach2 Deficiency Results in Excessive Tfh Cells and Aberrant GC B Cells in Mesenteric Lymph Nodes and Peyer's Patches}

Abnormal Tfh cell responses can lead to the development of autoimmunity $(19,26)$. We next examined whether Tfh cells and GCs were altered in Bach2 $2^{\triangle C D 4}$ mice. GCs are chronically induced in the mesenteric lymph nodes (MLNs) and Peyer's patches, as a result of continuous $B$ cell stimulation by a wide range of microbiota and food-derived antigens. For the next analyses, we used 8-10-week-old $B a c h 2^{\triangle C D 4}$ mice before they developed lymphoproliferative disease. The MLNs from Bach $2^{\triangle C D 4}$ mice had normal cellularity, but a lower proportion of $\mathrm{CD}^{+} \mathrm{T}$ cells when compared to the WT counterparts (Figure S1A). Consistent with previous reports, Bach $2^{\triangle C D 4}$ mice contained a higher frequency of CD $44^{\text {hi }}$ active/memory fraction in the $\mathrm{CD}^{+}$compartment within the MLNs (Figure S1B). However, Bach $2^{\triangle C D 4}$ mice had a significantly higher frequency and absolute number of follicular $\mathrm{T}$ cells $\left(\mathrm{CXCR} 5^{+} \mathrm{PD}-1^{+}\right.$or $\mathrm{CXCR}^{+} \mathrm{Bcl6}^{+}$) among $\mathrm{CD} 4^{+} \mathrm{T}$ cells than WT mice (Figure $2 \mathrm{~A}$ ). We next sought to determine whether expansion of follicular $\mathrm{T}$ cells in Bach $2^{\triangle C D 4}$ mice was selective to Tfh $\left(\mathrm{CXCR} 5^{+} \mathrm{PD}\right.$ $1^{+}$Foxp $3^{-}$) and/or Tfr $\left(\mathrm{CXCR}^{+} \mathrm{PD}-1^{+}\right.$Foxp $\left.3^{+}\right)$cells. We found that among $\mathrm{CXCR}^{+} \mathrm{PD}-1^{+}$follicular $\mathrm{T}$ cell compartments in Bach $2^{\triangle C D 4}$ mice, the ratio of $\mathrm{Tfh}$ to $\mathrm{Tfr}$ cells was shifted significantly toward the Tfh cell subset (Figure 2B), suggesting an expansion of Tfh cells to a larger extent than that of Tfr cells. Ablation of Bach 2 in $\mathrm{T}$ cells has been shown to decrease Foxp $3^{+}$Treg cells (7). Indeed, the percentage of Treg cells tended to decrease in the MLNs of Bach $2^{\triangle C D 4}$ mice, although with no significance (Figure S1C). The absolute number of
Treg cells in the MLNs of Bach $2^{\triangle C D 4}$ mice was significantly reduced because of their decreased $\mathrm{CD} 4^{+} \mathrm{T}$ cell compartment (Figure S1C). Interestingly, we found that the frequencies of Tfr cells among Foxp $3^{+} \mathrm{CD}^{+}$Treg cells and Tfh cells among Foxp $^{-} \mathrm{CD}^{+} \mathrm{T}$ cells increased by about two- and fourfold in the MLNs of Bach2 $2^{\triangle C D 4}$ mice compared to WT mice, respectively (Figure S1D). The absolute numbers, however, were significantly elevated only for Tfh but not Tfr cells in Bach $2^{\triangle C D 4}$ mice (Figure S1D). Thus, the Tfr/Tfh ratio, a critical factor dictating the magnitude of antibody production, was reduced in $B a c h 2^{\triangle C D 4}$ mice due to greater expansion of Th cells relative to Tfr cells.

We then investigated whether excessive Tfh cells induced abnormal GCs in the MLNs of Bach $2^{\triangle C D 4}$ mice. Bach $2^{\triangle C D 4}$ mice had a significantly higher frequency and absolute number of $\mathrm{Fas}^{+} \mathrm{CD} 38^{\mathrm{lo}} \mathrm{GC} \mathrm{B}$ cells in the MLNs when compared to WT mice (Figure 2C). Moreover, Bach $2^{\triangle C D 4}$ mice had a greater proportion of $\mathrm{CXCR} 4{ }^{\text {lo }} \mathrm{CD} 86^{\text {hi }}$ light zone cells among GC B cells (Figure 2C). The proportions of $\mathrm{IgG1}^{+}$and $\mathrm{IgE}^{+} \mathrm{GC} \mathrm{B}$ cells were significantly increased in the MLNs of Bach2 $2^{\triangle C D} 4$ mice (Figure 2D), indicating that Bach2 in Tfh cells affects antibody isotype switch within B cells. Similarly, excessive Tfh cells and deregulated GCs were observed in the Peyer's patches of Bach $2^{\triangle C D 4}$ mice (Figure S2). To further determine the cell-intrinsic role of Bach2 in constraining Tfh cells, we generated mixed bone marrow chimeras by reconstituting lethally irradiated CD45.1 ${ }^{+}$WT mice with a 4:1 ratio mixture of bone marrow cells from CD45.2 ${ }^{+}$Bach2-deficient and WT donor mice, respectively (Figure S3). Eight weeks after transplantation, we observed that CD45.2 ${ }^{+}$Bach2-deficient $\mathrm{CD}^{+} \mathrm{T}$ cells developed more Tfh cells compared to CD45.2 ${ }^{+} \mathrm{WT} \mathrm{CD}^{+} \mathrm{T}$ cells in the MLNs and Peyer's patches (Figure S3), indicating that Bach2 regulates Tfh cell formation intrinsically. In conclusion, Bach2 in T cells is critical to limit Tfh cell differentiation and regulate the GC responses in chronic GCs.

\section{Bach2 Deficiency in T Cells Enhances the Formation of Spontaneous GCs in the Spleen}

Spontaneous GCs are induced without immunization or infection, and contribute to steady-state antibody production. Aberrant spontaneous GCs produce pathogenic autoantibodies and have been described in many autoimmune diseases such as SLE (21). We next explored whether Bach2 deficiency in T cells affects the generation of spontaneous GCs. We found that 4-5month-old Bach $2^{\triangle C D 4}$ mice had significantly higher frequencies of $\mathrm{CXCR}^{+} \mathrm{PD}-1^{+}$follicular T cells in their spleens (Figure $3 \mathrm{~A}$ ). Among the follicular T cell compartment in Bach $2^{\triangle C D 4}$ mice, the Tfh to Tfr cell ratio shifted significantly toward the Tfh cell subset in their spleens (Figure 3A). Furthermore, the frequency of GC $\mathrm{B}$ cells was significantly elevated in the spleens of Bach $2^{\triangle C D 4}$ mice compared to WT mice (Figure 3B). Immunohistochemical staining further revealed that the spleens of Bach $2^{\triangle C D 4}$ mice contained considerably more and larger peanut agglutinin (PNA)-positive GCs than did their WT counterparts (Figure 3C). Although the frequencies of dark zone B cells among GC B cells 


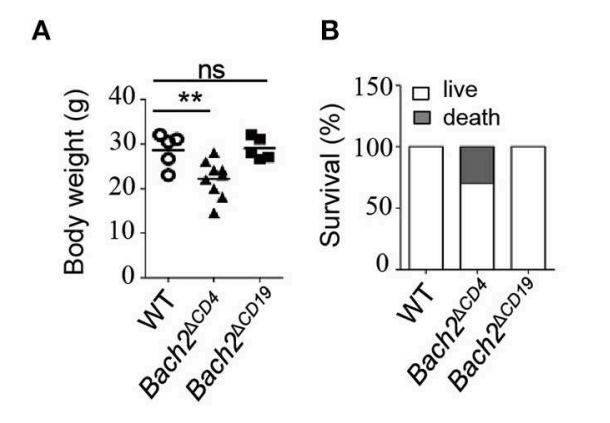

D

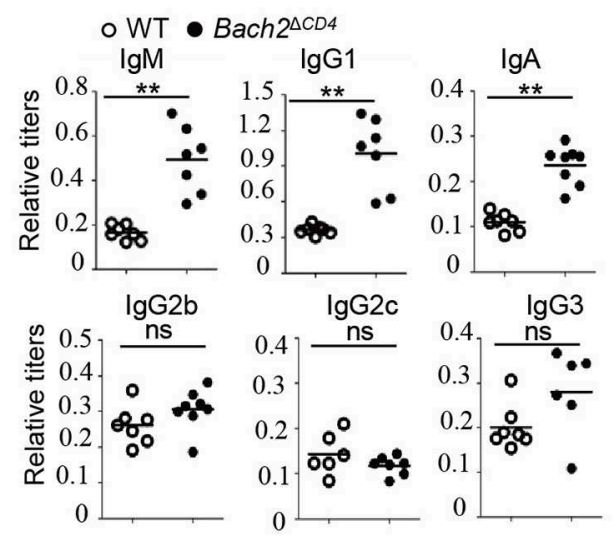

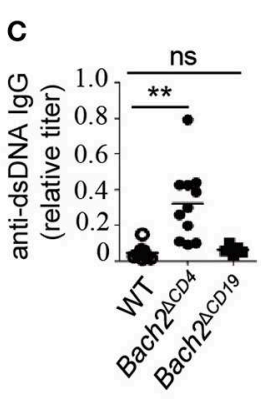

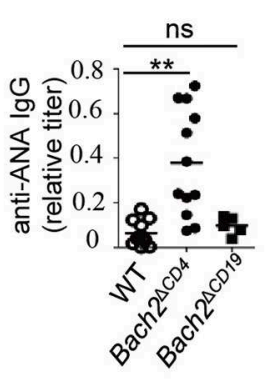

F

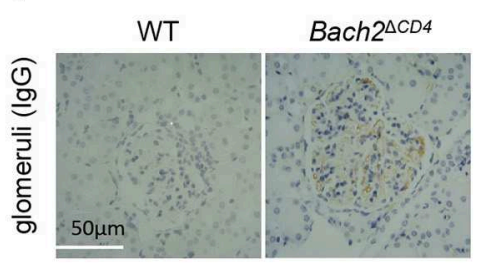

G

E o WT • Bach2 $\triangle \mathrm{CCD}$
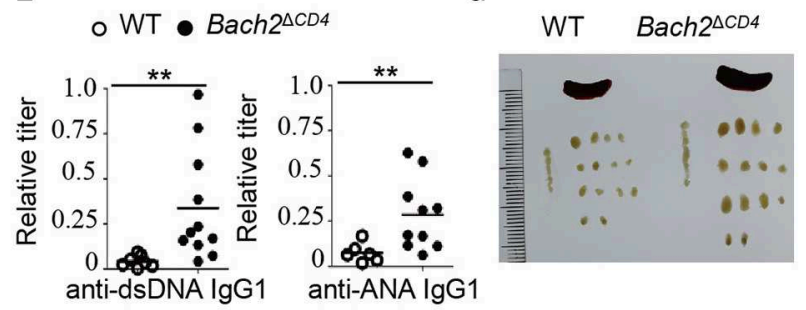

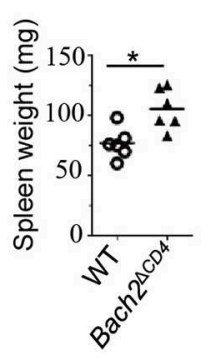

FIGURE 1 | Loss of Bach2 in T cells causes humoral autoimmunity. (A,B) Body weight (A) and survival rate (B) of wild-type (WT), Bach2 ${ }^{\Delta C D 4}$, or Bach2 ${ }^{\Delta C D 19}$ mice at 5 months of age. (C) Titer of anti-dsDNA antibodies and anti-nuclear antibodies (ANA) in the sera of WT, Bach2 ${ }^{\Delta C D 4}$, or Bach2 ${ }^{\Delta C D 19}$ mice at 2-3 months of age. (D) Titers of immunoglobulins in sera of WT and Bach2 ${ }^{\triangle C D 4}$ mice at 2-3 months of age. (E) Titers of anti-dsDNA and ANA IgG1 in the sera of WT and Bach2 ${ }^{\triangle C D} 4$ mice at 2-3 months of age. (F) Immunochemistry of lgG deposit in renal glomeruli. (G) Representative images (left) of spleen and lymph nodes of WT and Bach2 $\triangle \mathrm{CD} 4$ mice at 5 months of age. The weight of spleens from indicated mice is shown at the right. Each symbol represents one mouse; small horizontal lines indicate the mean; ns, not significant; ${ }^{\star} P<0.05$ and ${ }^{\star \star} P<0.01$ (two-tailed $t$-test).

in the spleen of Bach $2^{\triangle C D 4}$ mice were equivalent to that of WT mice (Figure 3B), the proportion of $\mathrm{IgG1}^{+}$and $\mathrm{IgE}^{+}$cells was significantly higher (Figure 3D). Interestingly, the accumulation of Tfh cells and GC B cells was not observed in the spleens of young Bach $2^{\triangle C D 4}$ mice at 6-8 weeks of age (data not shown). In conclusion, Bach 2 in $\mathrm{T}$ cells is required to limit the formation of spontaneous GCs under steady state.

\section{Bach2 Is Down-Regulated During Tfh Cell Differentiation and Directly Suppressed by BCL6}

A previous study showed that naive $\mathrm{CD} 4^{+} \mathrm{T}$ cells express higher levels of Bach 2 compared to effector/memory CD4 ${ }^{+}$cells (30). To better understand the role of Bach2 in Tfh cells, we first examined the mRNA abundance of Bach2 during Tfh cell differentiation. Quantitative RT-PCR revealed that Bach 2 mRNA abundance was markedly reduced during Tfh cell differentiation (Figure 4A). Then, we sought to figure out the mechanism by which Bach2 is suppressed in Tfh cells. The transcriptional repressor BCL6 is highly expressed in Tfh cells and acts as a master regulator of Tfh differentiation (15-17). Therefore, we hypothesized that Bach2 may be a direct target of BCL6. By analyzing published chromatin immunoprecipitation sequencing (ChIP-Seq) of human primary tonsillar Tfh cells (35), we identified multiple BCL6 binding peaks at the BACH2 gene promoter and gene body (Figure $4 \mathrm{~B}$ ). The binding of BCL6 at the BACH2 promoter region was confirmed by ChIP followed by quantitative PCR (Figure 4C). To investigate whether BCL6 represses Bach2 expression, WT and $B c l 6^{E R T 2 C r e}$ mice were immunized i.p. with SRBCs, a T-celldependent antigen, to induce Tfh cell response in the spleen. On day 8 after immunization, mice were administrated with one dose of tamoxifen by oral gavage to induce Cre activity for Bcl6 deletion in Tfh cells. Acute deletion of Bcl6 in Tfh cells led to an increase of Bach2 mRNA abundance (Figure 4D). Collectively, these results demonstrate that BCL6 directly binds to Bach2 and suppresses its transcription.

\section{Bach2 Represses Tfh-Related Genes Including C-Maf and Cxcr5}

To gain further insight into the mechanisms by which Bach2 inhibits Tfh cell differentiation, we compared the mRNA abundance of a group of key molecules known to be crucial for the differentiation of Tfh cells in WT and Bach2-deficient naive $\mathrm{CD} 4^{+} \mathrm{T}$ cells activated in vitro under unbiased conditions (Th0) or conditions that promote the differentiation of Tfh celllike (Tfh-like) cells. Bach 2 deficiency promotes activated $\mathrm{CD} 4^{+} \mathrm{T}$ 
A
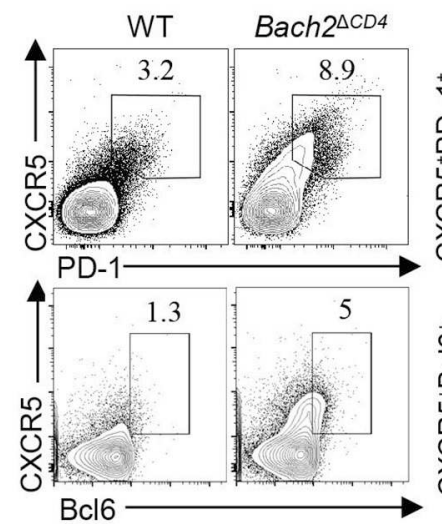

$\mathrm{Bcl} 6$
○ WT ^ Bach2 $2^{\triangle C D 4}$

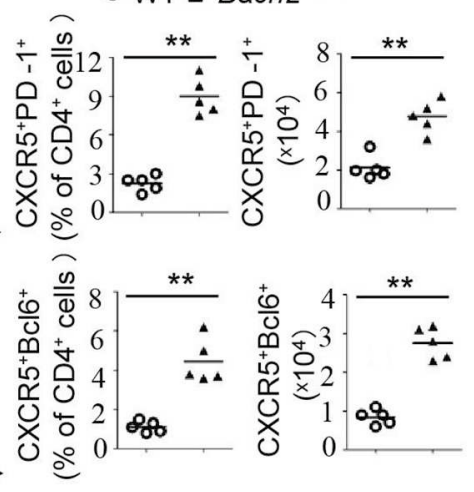

B
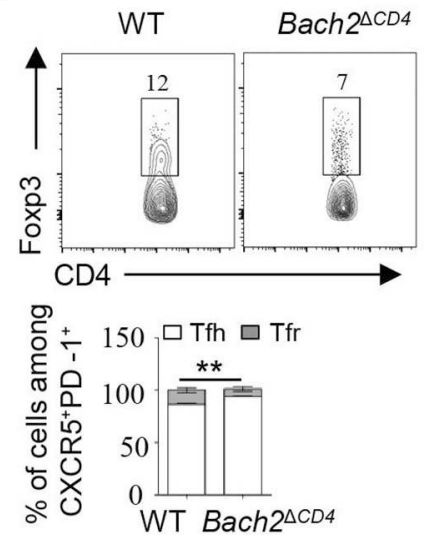

C
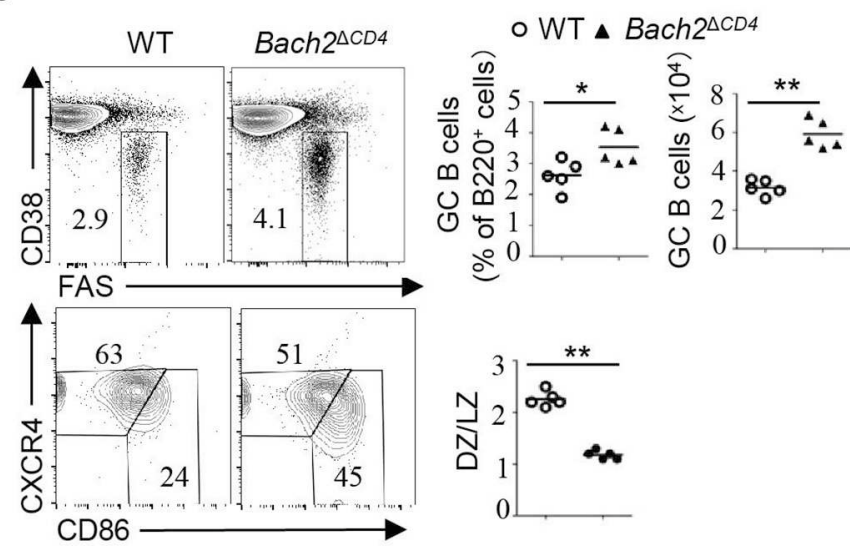

D
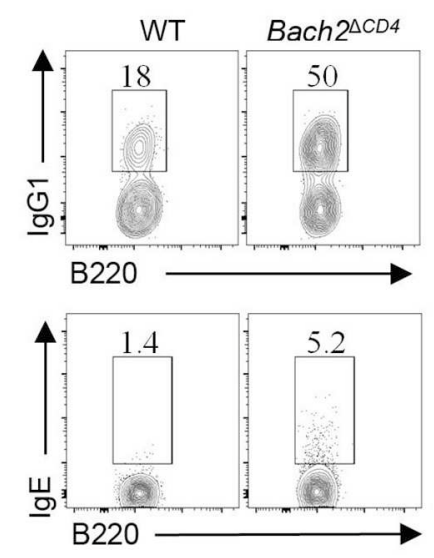

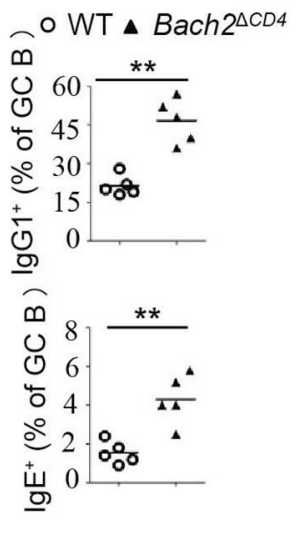

FIGURE 2 | Bach2 ${ }^{\triangle \mathrm{CD} 4}$ mice display excessive Tfh cells and aberrant GC B cells in the MLNs. Lymphocytes from the MLNs of WT and Bach2 $2^{\triangle \mathrm{CD} 4}$ mice at 2-3 months of age were subjected for analysis. (A) Representative flow cytometry plots, frequency quantification, and absolute number of CXCR5 ${ }^{+}$PD- $1^{+}$and

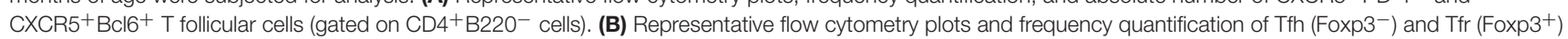
cells among CXCR5 ${ }^{+} \mathrm{PD}-1+\mathrm{CD} 4 \mathrm{~T}$ cells. (C) Representative flow cytometry plots, frequency quantification, and absolute number of $\mathrm{CD} 38^{\mathrm{lo} /-}$ Fas ${ }^{+} \mathrm{GC} B$ cells among splenic live B220+ cells. Quantification of the ratio of CD86 hi CXCR4lo light zone (LZ) to CD86 lo CXCR4hi dark zone (DZ) B cells among GC B cells (bottom). (D) Representative flow cytometry plots and frequency quantification of $\operatorname{lgG} 1^{+}$and $\lg \mathrm{E}^{+}$cells among splenic $\mathrm{GC} B$ cells. All data were from at least two independent experiments. Each symbol represents one mouse, and small horizontal lines indicate the mean. ns, not significant; ${ }^{*} P<0.05$ and ${ }^{* \star} P<0.01$ (two-tailed $t$-test).

cells to express high level of IL-4 (Figure 5A), in agreement with a previous report $(13,14)$. Interestingly, the mRNA levels of Cxcr5 and c-Maf were up-regulated by about 6 - and 32 -fold in Bach2deficient vs. WT $\mathrm{CD} 4^{+} \mathrm{T}$ cells cultured in Th0 cell condition, respectively (Figure 5A). Moreover, the mRNA levels of Cxcr5 and c-Maf were increased by about seven-fold in Bach2-deficient $\mathrm{CD}^{+} \mathrm{T}$ cells cultured under Tfh-like cell conditions (Figure 5A). However, the expression levels of other Tfh cell-related genes, including Bcl6, Batf, and Icos, were largely unchanged, suggesting that Bach2 may suppress Tfh differentiation mainly via repression of Cxcr5 and c-Maf. In line with this, Bach2-deficient non-Tfh $\left(\mathrm{CD} 4{ }^{+} \mathrm{CD} 44^{\text {high }} \mathrm{CXCR}^{-}{ }^{-} \mathrm{PD} 1^{-}\right)$cells expressed higher mRNA levels of c-Maf, Cxcr5, and $I L-4$, but not Bcl6 (Figure 5B). Unexpectedly, Bach2 appeared not to affect the expression of cMaf and Cxcr5 in Tfh cells (Figure 5B), and this is likely due to low abundance of Bach2 in these cells (Figure 4A). Finally, we observed that Bach2-deficient naïve $\mathrm{CD} 4^{+} \mathrm{T}$ cells contained a greater proportion of $\mathrm{CXCR}^{+}$cells and expressed higher c-Maf protein abundance in vivo (Figure 5C). The protein expression of CXCR5 and c-Maf was comparable between WT and Bach2deficient Th cells (Figure 5D).

We next investigated the molecular mechanism by which Bach2 suppresses $C x c r 5$ and c-Maf transcription. Bach2 is known to act primarily as a transcription repressor. By analyzing published Bach2 ChIP-Seq data in activated $\mathrm{CD}^{+} \mathrm{T}$ cells (13), we found that Bach2 was recruited to the intron region of $I L-4$, the promoter region of c-Maf and upstream of the promoter of Cxcr5 (Figure 5E). The binding of Bach2 at these loci were further confirmed by ChIP-qPCR in activated $\mathrm{CD} 4^{+}$ $\mathrm{T}$ cells (Figure 5E), indicating that Bach2 negatively and directly 
A
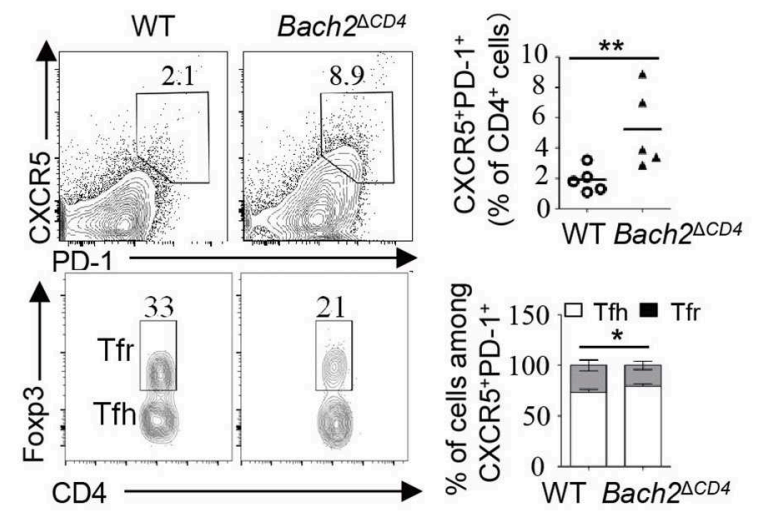

C

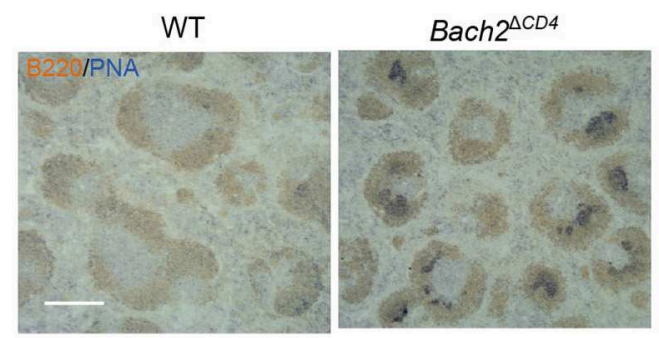

B
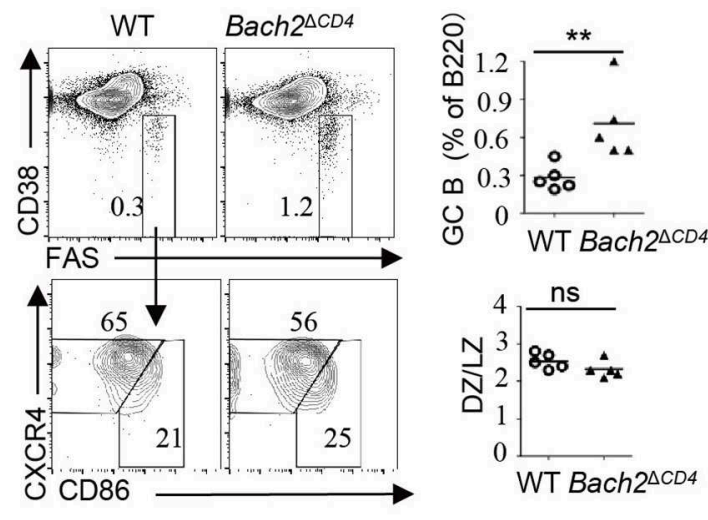

D

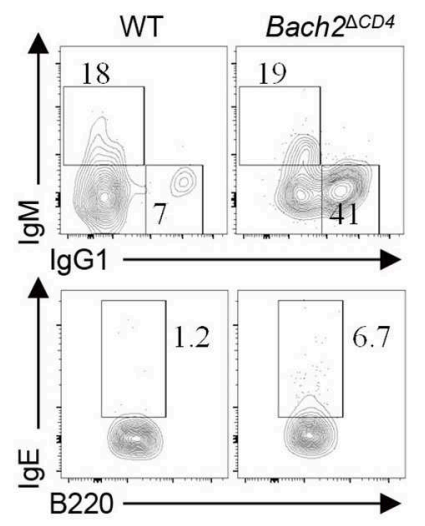

○ WT ^ Bach2 $\triangle \mathrm{CDA}$
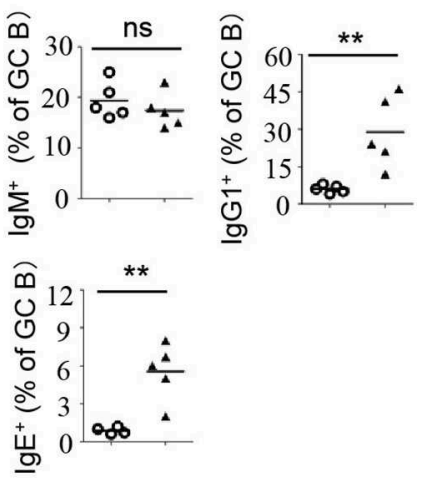

FIGURE $3 \mid$ Bach2 $2^{\triangle C D 4}$ mice develop spontaneous GCs in the spleens with age. The lymphocytes from the spleens of WT and Bach2 $\Delta C D 4$ mice at 3-5 months of age were subjected for analysis. (A) Representative flow cytometry plots and frequency quantification of splenic CXCR5 + PD- $1^{+} \mathrm{T}$ follicular cells (gated on $\mathrm{CD} 4^{+} \mathrm{B} 220^{-}$cells) (top). Representative flow cytometry plots and frequency quantification of $\mathrm{Tfh}\left(\mathrm{Foxp} 3^{-}\right.$) and $\mathrm{Tfr}\left(\mathrm{Foxp} 3^{+}\right.$) cells among CXCR5 ${ }^{+} \mathrm{PD}-1^{+} \mathrm{CD} 4 \mathrm{~T}$ cells (bottom). (B) Representative flow cytometry plots and frequency quantification of GC B cells among splenic live B220+ cells. Quantification of the ratio of $L Z$ to DZ B cells among GC B cells (bottom). (C) Representative PNA staining of splenic sections from WT and Bach2 ${ }^{\triangle C D} 4$ mice (scale bars, 1 mm). Blue, PNA; brown, B220. (D) Frequencies of $\operatorname{lgM}^{+}, \operatorname{lgG}_{1}+$, and $\operatorname{lgE}{ }^{+}$cells among GC B cells. All data were from at least two independent experiments. Each symbol represents one mouse, and small horizontal lines indicate the mean. ns, not significant; ${ }^{*} P<0.05$ and ${ }^{* *} P<0.01$ (two-tailed $t$-test).

regulates $I L-4, \mathrm{c}-M a f$, and Cxcr5. Interestingly, Bach2 bound to the IL-4 gene, but not Cxcr5 and c-Maf genes in Tfh-like cells (Figure S4), consistent with the observation that WT and Bach2-deficient Tfh cells expressed the similar levels of Cxcr5 and c-Maf (Figures 5B,D).

\section{Bach2 Deficiency Promotes Tfh Cells to Skew Toward IL-4-Producing Subset}

To further elucidate the molecular mechanisms by which Bach2 regulates Tfh cell differentiation in vivo, we performed RNA sequencing to compare the transcriptome between WT and Bach2-deficient Tfh cells. The global gene expression between WT and Bach2-deficient Tfh cells were highly concordant (Pearson $r^{2}=0.92$, three replicates for each group), and key molecules known to be critical for Tfh cell differentiation, including Cxcr5 and c-Maf, had similar expression in the two groups of Tfh cells. Then, we selected genes from published datasets (GEO accession codes GSE21379) that are up-regulated and down-regulated in Tfh cells relative to their expression in non-Tfh cells (38), for gene set enrichment analysis (GSEA) with our data. This analysis revealed that Bach2-deficient Tfh cells did not show significant enrichment for the genes up-regulated or down-regulated in the Tfh lineage (Figure 6A), further suggesting that Bach2-deficient Tfh cells are "true" Tfh cells. Only 356 genes were significantly $\left(p_{\text {adj }}<0.01\right.$; change in expression $\geq 2$-fold) up-regulated and 298 genes were down-regulated in Bach2-deficient Tfh cells (Figure 6B). Among them, we found that Bach2-deficienct Tfh cells expressed higher $I L-4$, but lower IFN- $\gamma$, IL17-f, and Foxp3 at mRNA levels (Figure 6B). Moreover, the Th2 master regulator Gata3 was also increased in Bach2deficienct Tfh cells (Figure 6B). Flow cytometry further revealed that Bach2-deficient Tfh cells contained a higher proportion of IL-4-secreting cells, but a lower frequency of IFN- $\gamma$-secreting cells, in both the MLNs and spleens (Figures 6C,D), indicating that Bach2 deficiency promotes Tfh cells to skew toward IL-4producing subset. 


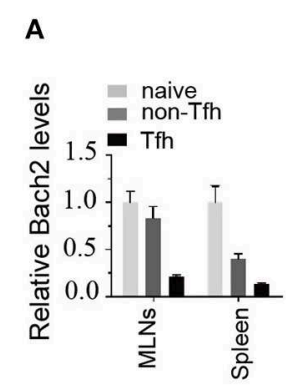

B

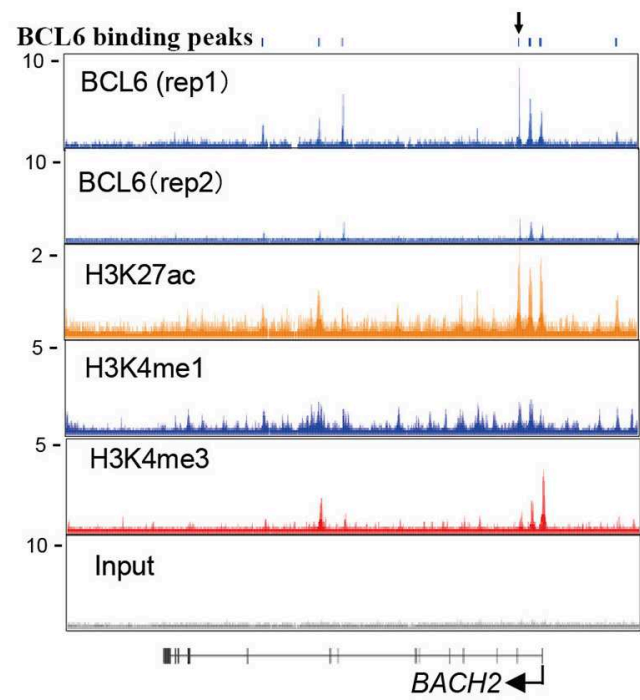

C

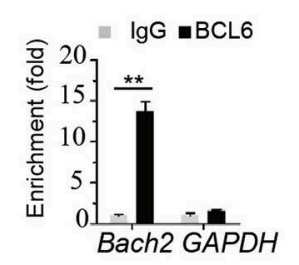

D

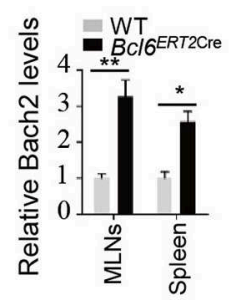

FIGURE 4 | Bach2 is down-regulated during Tfh cell differentiation and directly suppressed by BCL6. (A) Relative Bach2 mRNA abundance in naïve (CD44low $\left.\mathrm{CD} 62 \mathrm{~L}^{\text {high}}\right)$, non-Tfh (CD44 high $\left.\mathrm{CD} 62 \mathrm{~L}^{\text {low }} \mathrm{CXCR} 5^{-} \mathrm{PD} 1^{-}\right)$, and Tfh cells isolated from the MLNs and/or spleens of WT mice at 2 months of age, determined by RT-qPCR. (B) The illustration depicting ChIP-seq tracks of BCL6 and indicated histone marks at the BACH2 gene in primary human Tfh cells. BCL6 binding peaks are shown at the top. (C) ChIP-qPCR analysis of BCL6 binding peak indicated by arrow in (B). The fold enrichment was calculated relative to lgG. Data are mean \pm s.e.m. (D) The relative mRNA expression levels of Bach2 in Tfh cells sorted from the MLNs and spleens of 2-month-old WT and Bc/6 ERT2Cre mice 5 days post tamoxifen treatment. Data are mean \pm s.e.m. of two mice per group. ${ }^{\star} P<0.05$ and ${ }^{\star \star} P<0.01$ (two-tailed $t$-test).

\section{Heterozygous Bc/6 Deficiency Reduces Autoantibodies and Attenuates Pathology in $B a c h 2^{\triangle C D 4}$ Mice}

Autoantibodies result from a breakdown of tolerance mechanisms during B cell development, from T-cell-dependent or -independent $\mathrm{B}$ cell activation, or as a consequence of aberrant $\mathrm{GC}$ reactions. $\mathrm{BACH} 2$ has been shown to regulate many aspects of $\mathrm{T}$ cell differentiation and effector functions (1). Therefore, it is important to understand whether excessive Tfh cells account for the generation of autoantibodies and autoimmunity in Bach2 $2^{\triangle C D 4}$ mice. To this end, we crossed mice carrying LoxP-flanked Bcl6 alleles with Bach $2^{\triangle C D 4}$ mice to generate $B c l 6^{\mathrm{fl} /+} B a c h 2^{\Delta C D 4}$ mice. The $B c l 6$ heterozygosity was capable to limit the spontaneous and induced GC responses (20). As expected, the Bcl6 heterozygosity significantly reduced the frequencies of Tfh cells and chronic GC B cells in the MLNs of Bach $2^{\triangle C D 4}$ mice at 5 months of age (Figures $7 \mathrm{~A}, \mathbf{B}$ ). The expansion of spontaneous GC B cells in the spleens of these mice was also markedly attenuated, although the reduction of Tfh cells was not significant (Figures 7A,B). We then tested whether reduction in the chronic and spontaneous GC responses in $B c l 6^{\mathrm{H} /+}$ Bach $^{\Delta C D 4}$ mice was accompanied by reduced pathology. We found that the Bcl6 heterozygosity significantly increased the survival rate and prevented weight loss in Bach $2^{\triangle C D 4}$ mice at 5-6 months of age (Figure 7C). The titers of autoantibodies are often parallel with the disease severity and activity in various autoimmune diseases $(23,24)$. Morbid $B a c h 2^{\triangle C D 4}$ mice contained significantly higher titers of serum anti-dsDNA and anti-ANA antibodies when compared with the normal counterparts (Figure 7D). Although anti-dsDNA and anti-ANA antibodies were easily detected in the sera of $B c l 6^{\mathrm{fl} /+}$ Bach $2^{\triangle C D 4}$ mice, their titers were significantly lower than those in morbid Bach $2^{\triangle C D 4}$ mice (Figure 7D).

\section{DISCUSSION}

Our study gains new insights into Bach2-dependent control of humoral autoimmunity. Through our cell-type-specific Bach2deletion experiments, we confirm that Bach2 expression in $\mathrm{T}$ cells, but not in $\mathrm{B}$ cells, is essential for prevention of humoral autoimmunity. Bach2 restrains accumulation of Tfh cells, especially IL-4-producing subset, under chronic antigenic stimulation and steady state. Furthermore, we provide evidences to show that Bach2 prevents humoral autoimmunity, at least in part by inhibiting the generation of pathogenic Tfh cells. More recently, two groups reported that Bach2 limits Tfh cell differentiation in response to acute stimulation of foreign antigens $(39,40)$. In combination with our results, Bach2 appears to be an important negative regulator during Tfh cell differentiation under various conditions. In addition to Tfh cells, Bach2 instructs the differentiation and effector functions of other T cell subsets including Treg and Th17 cells. Deregulated Treg and Th17 cells play prominent roles in autoimmunity. We observed partial loss of Treg cells in Bach $2^{\triangle C D 4}$ mice. It is likely that these mice also harbor pathogenic Th17 cells. These abnormalities may significantly contribute to autoimmunity in Bach $2^{\triangle C D 4}$ mice. 


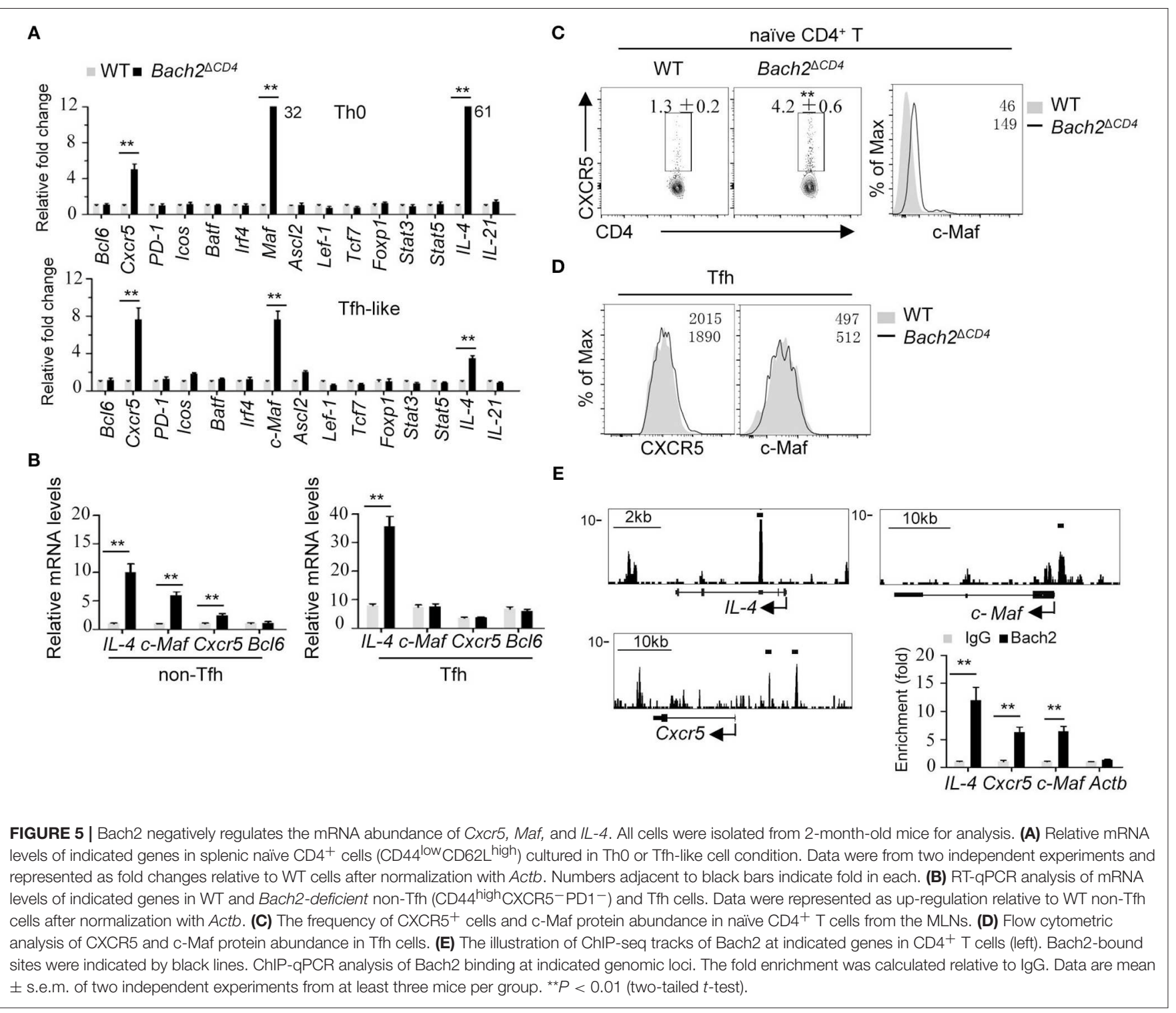

CXCR5 is a lineage-defining marker of Tfh cells, and Tfh cell differentiation is initiated by CXCR5 up-regulation $(15,16)$. Bach2 was reported to directly suppress Cxcr5 transcription (39). This conclusion was further confirmed in our study. In addition, we found that Bach2 is capable to directly repress $c$-Maf, a key regulator of Tfh cells. c-Maf is up-regulated during Tfh cell differentiation and facilitates the expression of many Tfh-related genes including Cxcr5, Icos, Pdcd-1, and IL-21 (32-34). Loss of c-Maf expression in the $\mathrm{T}$ cell compartment leads to defective development of Tfh cells in response to both antigen/adjuvant vaccinations and commensal intestinal bacteria (34). Thus, it is conceivable here that Bach2 deficiency results in aberrant Tfh cell formation mainly via up-regulation of c-Maf and CXCR5. Unexpectedly, although ectopic expression of Bach2 was shown to repress Bcl6 expression in differentiated Tfh cells induced by acute immunization with protein antigen (40), Bach2 deletion had no significant effect on Bcl6 mRNA abundance in Tfh cells induced by chronic antigenic stimulation. The different results may be due to different experimental settings.

Bach2 is highly expressed in GC B cells and is required for antibody class switching and blockade of plasma cell differentiation $(8,9)$. In contrast, Bach2 is gradually downregulated during Tfh cell differentiation and maintained at low levels in differentiated Tfh cells (Figure 4A). Currently, little is known about the transcriptional control of Bach2 in T cells. BCL6 may be a crucial transcriptional factor that binds to the Bach2 gene locus and suppresses its transcription (Figures 4B,C). The generation and function of Tfh cells are regulated at multiple stages. Bach2 is likely to act mainly at the early phase to limit aberrant Tfh formation. This is evidenced by the observation that Bach2 directly suppresses c-Maf and Cxcr5 levels in non-Tfh cells, but not in Tfh cells. Low Bach2 levels may be required for Tfh cells to maintain their identity, supported by the recent finding that ectopic overexpression of Bach2 in murine Tfh cells led to a 
A

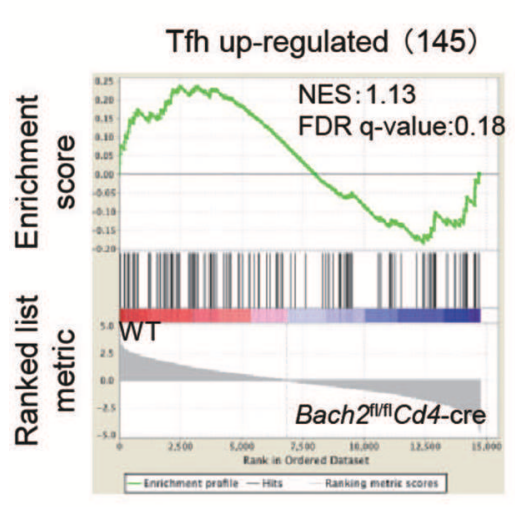

B

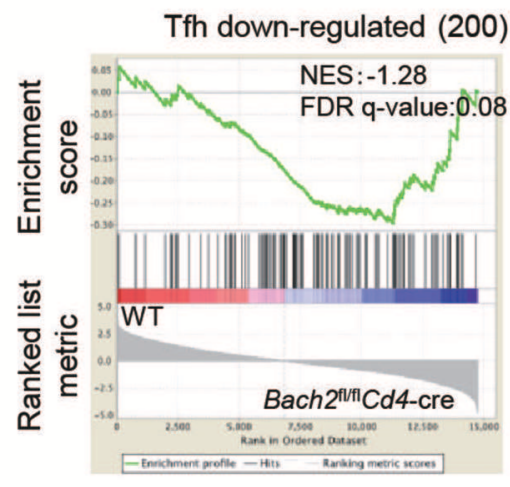

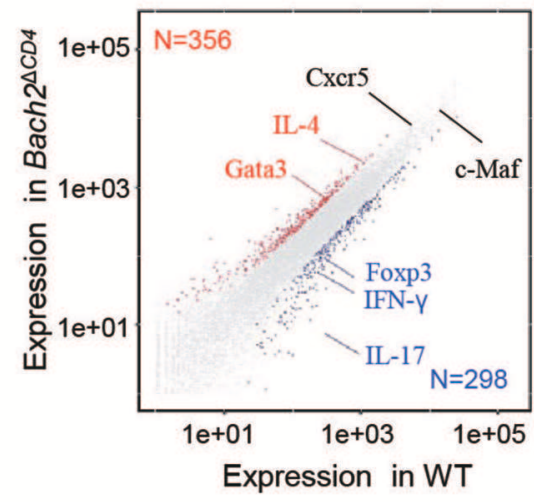

C
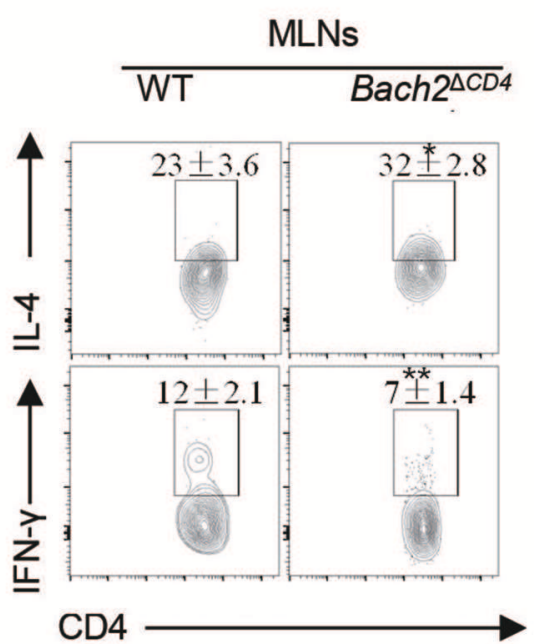

D

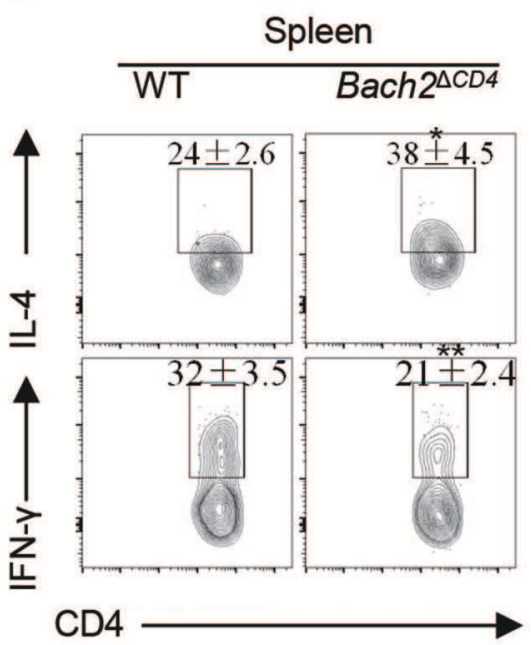

FIGURE 6 | Bach2-deficient Th cells are skewed IL-4-producing subset. Two- to 3-month-old mice were used for analysis. (A) GSEA analysis of gene signatures up-regulated or down-regulated in Tfh cells relative to their expression in non-Tfh cells, from published data (GEO accession code: GSE21379). (B) Scatterplot of genes up-regulated (red) or down-regulated (blue) in Bach2-deficient Tfh cells vs. WT cells. Select genes of interest are labeled. (C,D) Representative flow cytometry plots and quantification of IL-4 and IFN- $\gamma$-secreting Tfh subsets (gated in CXCR5 ${ }^{+}$PD- $1^{+}$T follicular cells) in the MLNs (C) and spleens (D). Data are mean \pm s.e.m. of two independent experiments from at least three mice per group. ${ }^{\star} P<0.05$ and ${ }^{\star \star} P<0.01$ (two-tailed $t$-test).

rapid loss of their phenotype and subsequent breakdown of the GC response (40). Thus, the dynamic expression of Bach2 in B cells and $\mathrm{T}$ cells could be crucial in instructing proper germinal center responses.

Tfh cells are heterogeneous cell populations, and some Tfh cells are capable of expressing Th1- or Th2-signature cytokines, IFN- $\gamma$ or IL-4, both of which contribute to the regulation of B cell antibody class switching within GCs. However, the mechanisms regulating IFN- $\gamma / \mathrm{IL}-4$-producing subset distribution in Tfh cells remain elusive. Bach2-deficient Tfh cells are skewed toward the IL-4-secreting subset, subsequently resulting in a greater proportion of $\mathrm{IgGl}^{+}$and $\mathrm{IgE}^{+} \mathrm{B}$ cells. To our knowledge, Bach2 is the first reported factor that regulates the balance of $\mathrm{Tfh}$ subsets. As the GC response evolves, differentiated Tfh cells extinguish IL-21 secretion and switch to IL-4 production (41). The switching may be repressed by Bach2 because Bach2 inhibits
IL-4 expression in Tfh cells. Mechanistically, Bach2 directly binds to the regulatory region of $I L-4$ to inhibit its transcription. In addition, Bach2 may indirectly suppress $I L-4$ transcription via down-regulation of Gata3. IL-4-secreting Tfh cells can originate from Th2 cells in response to chronic antigens such as helminth (42). It is possible that Bach2 specifically represses the conversion of Th2 into IL-4-producing Tfh cells in the lymphoid tissues in the presence of continuous antigenic stimulations. Further experiments are needed to test this hypothesis.

Genetic polymorphisms in the BACH2 gene locus are associated with numerous autoimmune and allergic diseases in human. Our genetics study in mice suggests that humans carrying the genetic variations in the $B A C H 2$ gene may develop autoimmune diseases by inducing excessive pathogenic Tfh cells. Targeting Tfh cells may represent an effective therapeutic strategy for these patients. 


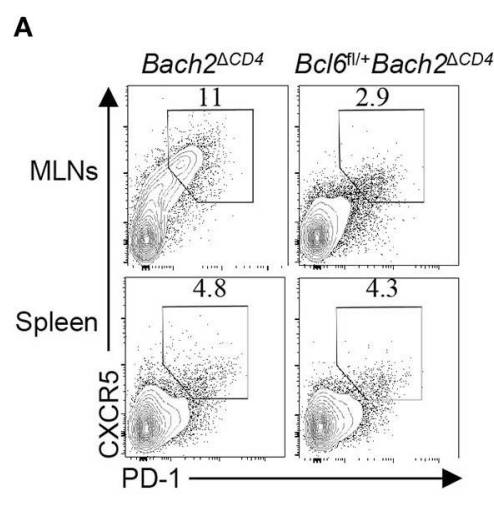

C

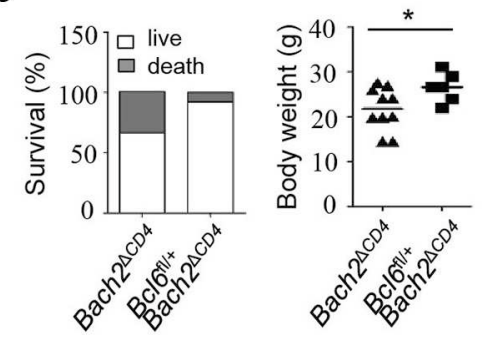

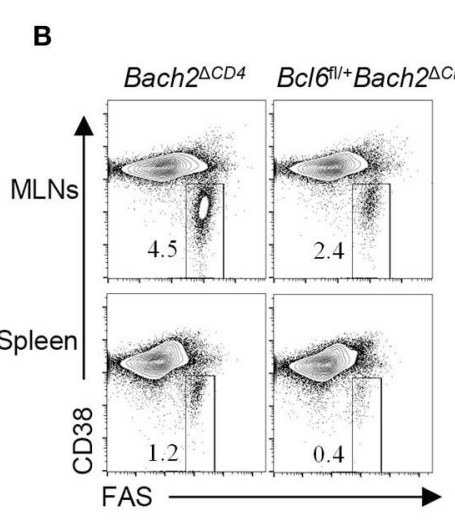

- Bach2 $2^{\triangle C D 4}$

$B c / 6^{f l /+} B a c h 2^{\triangle C D 4}$

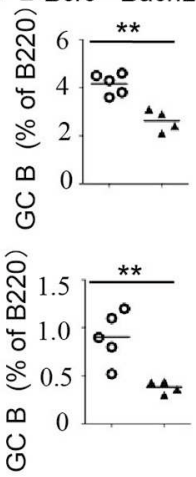

D

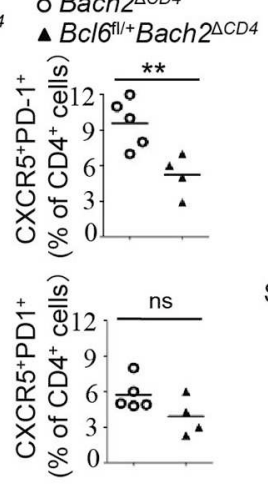

$\triangle B c / 6^{f l+} B a c h 2^{\triangle C D}$

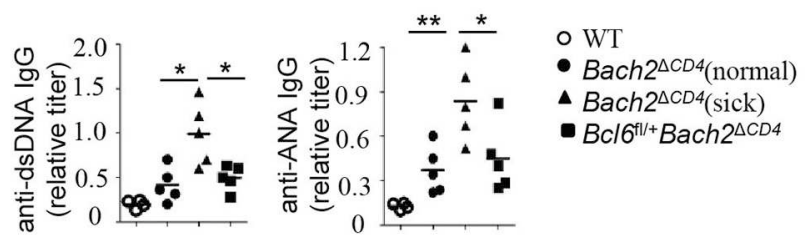

FIGURE 7 | The Bcl6 heterozygosity significantly reduced autoantibodies and pathology. (A,B) The frequencies of Tfh and GC B cells in the MLNs and spleens from

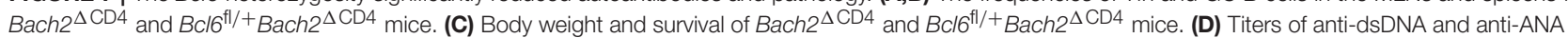
antibodies in sera from Bach2 $2^{\Delta C D 4}$ and $B c / 6^{f l /}+B a c h 2^{\Delta C D 4}$ mice. All mice were analyzed at 5-6 months of age. Each symbol represents one mouse; small horizontal lines indicate the mean. ns, not significant; ${ }^{*} P<0.05$ and ${ }^{* *} P<0.01$ (two-tailed $t$-test).

\section{DATA AVAILABILITY}

The RNA-seq data reported in this paper have been deposited in the NCBI Gene Expression Omnibus under accession number GEO135087.

\section{AUTHOR CONTRIBUTIONS}

$\mathrm{HZ}$ and $\mathrm{QH}$ conducted most of the experiments and analyzed the data. MZ and ZZ conducted RNA-seq analysis. FY and $\mathrm{CP}$ performed immunochemistry and ELISA. CH conceived the idea for the project, supervised the study, and wrote the manuscript.

\section{REFERENCES}

1. Richer MJ, Lang ML, Butler NS. T cell fates zipped up: how the Bach2 basic leucine zipper transcriptional repressor directs $\mathrm{T}$ cell differentiation and function. J Immunol. (2016) 197:1009-15. doi: 10.4049/jimmunol.1600847

2. Ferreira MA, Matheson MC, Duffy DL, Marks GB, Hui J, Le Souef P, et al. Identification of IL6R and chromosome 11q13.5 as risk loci for asthma. Lancet. (2011) 378:1006-14. doi: 10.1016/S0140-6736(11)60874-X

3. Jin Y, Birlea SA, Fain PR, Ferrara TM, Ben S, Riccardi SL, et al. Genome-wide association analyses identify 13 new susceptibility loci for generalized vitiligo. Nat Genet. (2012) 44:676-80. doi: 10.1038/ng.2272

4. International Multiple Sclerosis Genetics Consortium, Wellcome Trust Case Control Consortium, Sawcer S, Hellenthal G, Pirinen M, Spencer CC, et al.

\section{FUNDING}

This work was supported in part by the National Key R\&D Program of China (2018YFC0115900) to $\mathrm{CH}$, the 1000 Youth Elite Program, the National Natural Science Foundation of China (31870872) to CH, and Doctoral Innovation Fund Projects from Shanghai Jiao Tong University School of Medicine to HZ.

\section{SUPPLEMENTARY MATERIAL}

The Supplementary Material for this article can be found online at: https://www.frontiersin.org/articles/10.3389/fimmu. 2019.02050/full\#supplementary-material

Genetic risk and a primary role for cell-mediated immune mechanisms in multiple sclerosis. Nature. (2011) 476:214-9. doi: 10.1038/nature10251

5. Cooper JD, Smyth DJ, Smiles AM, Plagnol V, Walker NM, Allen JE, et al. Meta-analysis of genome-wide association study data identifies additional type 1 diabetes risk loci. Nat Genet. (2008) 40:1399-401. doi: 10.1038/ ng.249

6. Morris DL, Sheng Y, Zhang Y, Wang YF, Zhu Z, Tombleson P, et al. Genomewide association meta-analysis in Chinese and European individuals identifies ten new loci associated with systemic lupus erythematosus. Nat Genet. (2016) 48:940-6. doi: 10.1038/ng.3603

7. Roychoudhuri R, Hirahara K, Mousavi K, Clever D, Klebanoff CA, Bonelli $\mathrm{M}$, et al. BACH2 represses effector programs to stabilize $\mathrm{T}(\mathrm{reg})$-mediated immune homeostasis. Nature. (2013) 498:506-10. doi: 10.1038/nature12199 
8. Muto A, Tashiro S, Nakajima O, Hoshino H, Takahashi S, Sakoda E, et al. The transcriptional programme of antibody class switching involves the repressor Bach2. Nature. (2004) 429:566-71. doi: 10.1038/nature02596

9. Huang C, Geng H, Boss I, Wang L, Melnick A. Cooperative transcriptional repression by BCL6 and BACH2 in germinal center B-cell differentiation. Blood. (2014) 123:1012-20. doi: 10.1182/blood-2013-07-518605

10. Tsukumo S, Unno M, Muto A, Takeuchi A, Kometani K, Kurosaki $\mathrm{T}$, et al. Bach2 maintains $\mathrm{T}$ cells in a naive state by suppressing effector memory-related genes. Proc Nat Acad Sci USA. (2013) 110:1073540. doi: 10.1073/pnas.1306691110

11. Kim EH, Gasper DJ, Lee SH, Plisch EH, Svaren J, Suresh M. Bach2 regulates homeostasis of Foxp3+ regulatory $\mathrm{T}$ cells and protects against fatal lung disease in mice. J Immunol. (2014) 192:985-95. doi: 10.4049/jimmunol.1302378

12. Yu X, Lao Y, Teng XL, Li S, Zhou Y, Wang F, et al. SENP3 maintains the stability and function of regulatory $\mathrm{T}$ cells via BACH2 deSUMOylation. Nat Commun. (2018) 9:3157. doi: 10.1038/s41467-018-05676-6

13. Kuwahara M, Ise W, Ochi M, Suzuki J, Kometani K, Maruyama S, et al. Bach2Batf interactions control Th2-type immune response by regulating the IL-4 amplification loop. Nat Commun. (2016) 7:12596. doi: 10.1038/ncomms12596

14. Kuwahara M, Suzuki J, Tofukuji S, Yamada T, Kanoh M, Matsumoto A, et al. The Menin-Bach2 axis is critical for regulating CD4 Tcell senescence and cytokine homeostasis. Nat Commun. (2014) 5:3555. doi: 10.1038/ncomms4555

15. Crotty S. Follicular helper CD4T cells (TFH). Ann Rev Immun. (2011) 29:621-63. doi: 10.1146/annurev-immunol-031210-101400

16. Vinuesa CG, Linterman MA, Yu D, MacLennan IC. Follicular helper $\mathrm{T}$ cells. Ann Rev Immun. (2016) 34:33568. doi: 10.1146/annurev-immunol-041015-055605

17. Ueno $\mathrm{H}$, Banchereau J, Vinuesa CG. Pathophysiology of $\mathrm{T}$ follicular helper cells in humans and mice. Nat Immunol. (2015) 16:142-52. doi: 10.1038/ni.3054

18. Vinuesa CG, Sanz I, Cook MC. Dysregulation of germinal centres in autoimmune disease. Nat Rev Immunol. (2009) 9:845-57. doi: 10.1038/nri2637

19. Craft JE. Follicular helper T cells in immunity and systemic autoimmunity. Nat Rev Rheumatol. (2012) 8:337-47. doi: 10.1038/nrrheum.2012.58

20. Linterman MA, Rigby RJ, Wong RK, Yu D, Brink R, Cannons JL, et al. Follicular helper T cells are required for systemic autoimmunity. J Exp Med. (2009) 206:561-76. doi: 10.1084/jem.20081886

21. Vinuesa CG, Cook MC, Angelucci C, Athanasopoulos V, Rui L, Hill $\mathrm{KM}$, et al. A RING-type ubiquitin ligase family member required to repress follicular helper T cells and autoimmunity. Nature. (2005) 435:4528. doi: 10.1038/nature03555

22. Vaeth M, Eckstein M, Shaw PJ, Kozhaya L, Yang J, Berberich-Siebelt F, et al. Store-operated $\mathrm{Ca}(2+)$ entry in follicular $\mathrm{T}$ cells controls humoral immune responses and autoimmunity. Immunity. (2016) 44:135064. doi: 10.1016/j.immuni.2016.04.013

23. Zhang X, Lindwall E, Gauthier C, Lyman J, Spencer N, Alarakhia A, et al. Circulating CXCR5+CD4+helper $\mathrm{T}$ cells in systemic lupus erythematosus patients share phenotypic properties with germinal center follicular helper $\mathrm{T}$ cells and promote antibody production. Lupus. (2015) 24:909-17. doi: 10.1177/0961203314567750

24. Choi JY, Ho JH, Pasoto SG, Bunin V, Kim ST, Carrasco S, et al. Circulating follicular helper-like $\mathrm{T}$ cells in systemic lupus erythematosus: association with disease activity. Arthritis Rheumatol. (2015) 67:988-99. doi: 10.1002/art.39020

25. Ma CS, Deenick EK, Batten M, Tangye SG. The origins, function, and regulation of $\mathrm{T}$ follicular helper cells. J Exp Med. (2012) 209:124153. doi: 10.1084/jem.20120994

26. Crotty $\mathrm{S}$. T follicular helper cell differentiation, function, and roles in disease. Immunity. (2014) 41:529-42. doi: 10.1016/j.immuni.2014.10.004
27. Liu X, Nurieva RI, Dong C. Transcriptional regulation of follicular T-helper (Tfh) cells. Immunol Rev. (2013) 252:139-45. doi: 10.1111/imr.12040

28. Jogdand GM, Mohanty S, Devadas S. Regulators of Tfh cell differentiation. Front Immunol. (2016) 7:520. doi: 10.3389/fimmu.2016.00520

29. Yu D, Rao S, Tsai LM, Lee SK, He Y, Sutcliffe EL, et al. The transcriptional repressor Bcl-6 directs $\mathrm{T}$ follicular helper cell lineage commitment. Immunity. (2009) 31:457-68. doi: 10.1016/j.immuni.2009.07.002

30. Nurieva RI, Chung Y, Martinez GJ, Yang XO, Tanaka S, Matskevitch TD, et al. Bcl6 mediates the development of T follicular helper cells. Science. (2009) 325:1001-5. doi: 10.1126/science. 1176676

31. Johnston RJ, Poholek AC, DiToro D, Yusuf I, Eto D, Barnett B, et al. Bcl6 and Blimp-1 are reciprocal and antagonistic regulators of $\mathrm{T}$ follicular helper cell differentiation. Science. (2009) 325:1006-10. doi: 10.1126/science.1175870

32. Bauquet AT, Jin H, Paterson AM, Mitsdoerffer M, Ho IC, Sharpe AH, et al. The costimulatory molecule ICOS regulates the expression of c-Maf and IL-21 in the development of follicular T helper cells and TH-17 cells. Nat Immunol. (2009) 10:167-75. doi: 10.1038/ni.1690

33. Kroenke MA, Eto D, Locci M, Cho M, Davidson T, Haddad EK, et al. Bcl6 and Maf cooperate to instruct human follicular helper CD4 T cell differentiation. $J$ Immunol. (2012) 188:3734-44. doi: 10.4049/jimmunol.1103246

34. Andris F, Denanglaire S, Anciaux M, Hercor M, Hussein H, Leo O. The transcription factor c-Maf promotes the differentiation of follicular helper $\mathrm{T}$ cells. Front Immunol. (2017) 8:480. doi: 10.3389/fimmu.2017.00480

35. Kim CJ, Lee CG, Jung JY, Ghosh A, Hasan SN, Hwang SM, et al. The transcription factor Ets1 suppresses $\mathrm{T}$ follicular helper type 2 cell differentiation to halt the onset of systemic lupus erythematosus. Immunity. (2018) 49:1034-48.e8. doi: 10.1016/j.immuni.2018.10.012

36. Peng C, Hu Q, Yang F, Zhang H, Li F, Huang C. BCL6-mediated silencing of $\mathrm{PD}-1$ ligands in germinal center B cells maintains follicular $\mathrm{T}$ cell population. J Immunol. (2019) 202:704-13. doi: 10.4049/jimmunol.1800876

37. Hatzi K, Nance JP, Kroenke MA, Bothwell M, Haddad EK, Melnick A, et al. BCL6 orchestrates Tfh cell differentiation via multiple distinct mechanisms. J Exp Med. (2015) 212:539-53. doi: 10.1084/jem.20141380

38. Yusuf I, Kageyama R, Monticelli L, Johnston RJ, Ditoro D, Hansen K, et al. Germinal center $\mathrm{T}$ follicular helper cell IL-4 production is dependent on signaling lymphocytic activation molecule receptor (CD150). J Immunol. (2010) 185:190-202. doi: 10.4049/jimmunol.0903505

39. Geng J, Wei H, Shi B, Wang YH, Greer BD, Pittman M, et al. Bach2 negatively regulates $\mathrm{T}$ follicular helper cell differentiation and is critical for CD4 $(+) \mathrm{T}$ cell memory. J Immunol. (2019) 202:2991-8. doi: 10.4049/jimmunol.1801626

40. Lahmann A, Kuhrau J, Fuhrmann F, Heinrich F, Bauer L, Durek P, et al. Bach2 controls $\mathrm{T}$ follicular helper cells by direct repression of Bcl-6. J Immunol. (2019) 202:2229-39. doi: 10.4049/jimmunol.1801400

41. Weinstein JS, Herman EI, Lainez B, Licona-Limon P, Esplugues E, Flavell $\mathrm{R}$, et al. TFH cells progressively differentiate to regulate the germinal center response. Nat Immunol. (2016) 17:1197-205. doi: 10.1038/ni.3554

42. Glatman Zaretsky A, Taylor JJ, King IL, Marshall FA, Mohrs M, Pearce EJ. $\mathrm{T}$ follicular helper cells differentiate from Th2 cells in response to helminth antigens. J Exp Med. (2009) 206:991-9. doi: 10.1084/jem.20090303

Conflict of Interest Statement: The authors declare that the research was conducted in the absence of any commercial or financial relationships that could be construed as a potential conflict of interest.

Copyright (c) 2019 Zhang, Hu, Zhang, Yang, Peng, Zhang and Huang. This is an open-access article distributed under the terms of the Creative Commons Attribution License (CC BY). The use, distribution or reproduction in other forums is permitted, provided the original author(s) and the copyright owner(s) are credited and that the original publication in this journal is cited, in accordance with accepted academic practice. No use, distribution or reproduction is permitted which does not comply with these terms. 